\title{
Evaluation of Emplacement Sensors for Detecting Radiation and Volatile Organic Compounds and for Long-term Monitoring Access Tubes for the BWCS
}

\author{
D. L. Lord \\ R. H. Averill
}

Published October 1997

Idaho National Engineering and Environmental Laboratory

Lockheed Martin Idaho Technologies Company

Idaho Falls, Idaho 83415

DISTRIEUTION OF THS DOCUMENT IS URUMARE ph

Prepared for the

U.S. Department of Energy

Assistant Secretary for Environmental Management

Under DOE Idaho Operations Office

Contract DE-AC07-94ID13223 


\section{DISCLAMMER}

This report was prepared as an account of work sponsored by an agency of the United States Government. Neither the United States Government nor any agency thereof, nor any of their employees, makes any warranty, express or implied, or assumes any legal liability or responsibility for the accuracy, completeness, or usefulness of any information, apparatus, product, or process disclosed, or represents that its use would not infringe privately owned rights. Reference herein to any specific commercial product, process, or service by trade name, trademark, manufacturer, or otherwise does not necessarily constitute or imply its endorsement, recommendation, or favoring by the United States Government or any agency thereof. The views and opinions of authors expressed herein do not necessarily state or reflect those of the United States Government or any agency thereof. 


\section{DISCLAIMER}

Portions of this document may be illegible electronic image products. Images are produced from the best available original document. 


\section{ABSTRACT}

This document evaluates sensors for detecting contaminants in the excavated waste generated by the Buried Waste Containment System (BWCS).

The Barrier Placement Machine (BPM) removes spoils from under a landfill or plume and places it on a conveyor belt on the left and right sides of the BPM. The spoils will travel down the conveyor belts past assay monitors and be deposited on top of the site being worked. The belts are $5 \mathrm{ft}$ wide and transport approximately $15 \mathrm{ft}^{3} /$ minute of spoils. This corresponds to a $10 \mathrm{ft}$ per hour BPM advance rate. With a 2 in. spoils height the belt speed would be 3.6 in. per second.

The spoils being removed are expected to be "clean" (no radiation or volatile organics above background levels). To ensure that the equipment is not digging through a contaminated area, assay equipment will monitor the spoils for radiation and volatile organic compounds (VOCs).

The radiation monitors will check for gross radiation indication. Upon detection of radiation levels above a predetermined setpoint, further evaluation will be performed to determine the isotopes present and their quantity. This will require hand held monitors and a remote monitoring station.

Simultaneously, VOC monitors will monitor for predetermined volatile/semi-volatile organic compounds. A Fourier-Transform Infrared Spectrometer (FTIR) monitor is recommended for this operation. Specific site requirements and regulations will determine setpoints and operation scenarios. If VOCs are detected, the data will be collected and recorded. A flat panel display will be mounted in the BPM operator's cab showing the radionuclide and VOC monitoring data.

As the BPM advances, a 3-in. diameter PVC tube will be placed on the bottom of the barrier slot in front of the 12 to 16 -in. containment barrier being emplaced. These tubes are known as long-term monitoring access tubes.

Radiation and VOC monitoring instrumentation can be inserted in the tubes for long-term monitoring of the landfill or plume site. 


\section{CONTENTS}

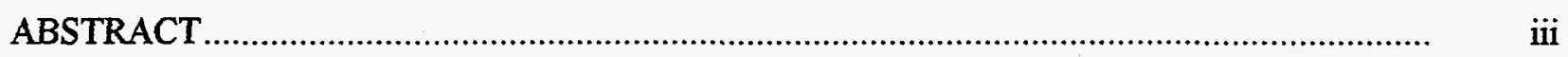

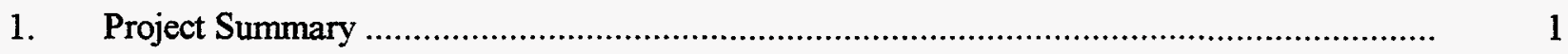

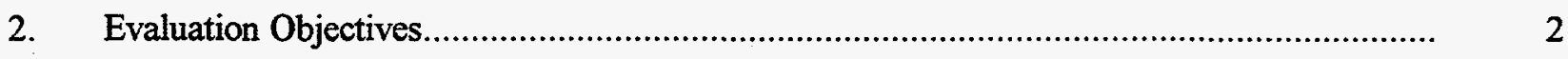

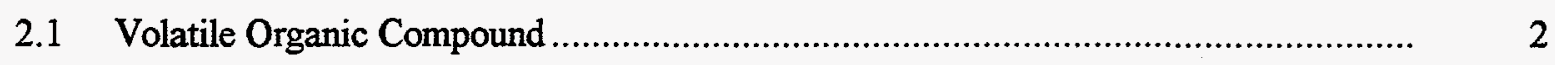

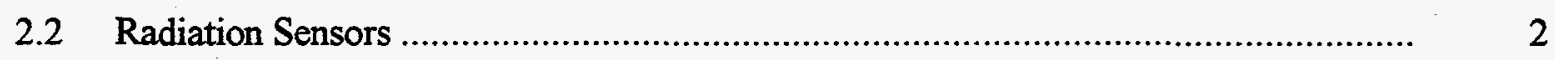

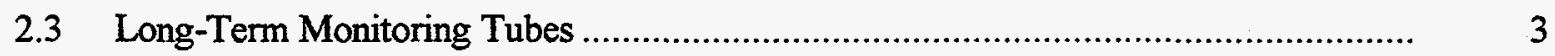

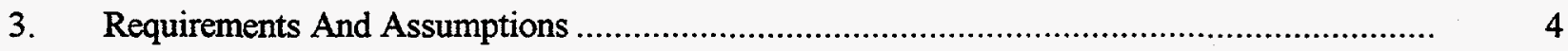

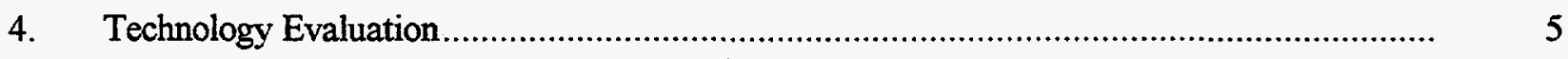

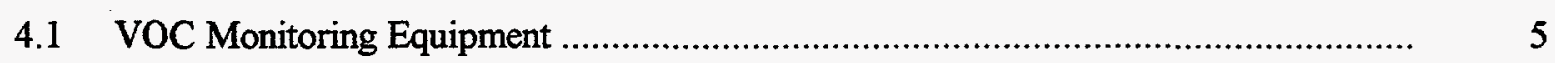

4.1.1 Gas Chromatography/ Mass Spectrometry (GC/MS)................................. 5

4.1.2 Acoustic-Optic Tunable Filter (AOTF) Infrared Spectrometer ..................... 5

4.1.3 Heated Carbon Analyzer with Photo Accoustic Infrared Spectrometry (PAS). 5

4.1.4 Fourier-Transform Infrared Spectrometer (FTIR) System............................ 7

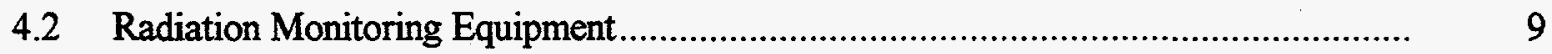

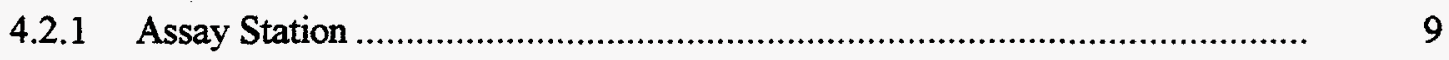

4.2.2 Survey Monitors ......................................................................... 10

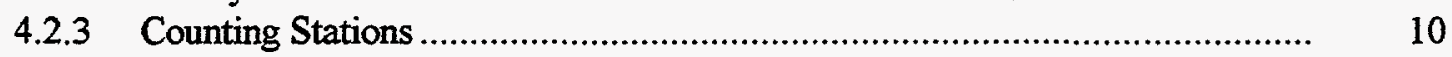

4.3 Long-term Monitoring Access Tubes ........................................................... 11

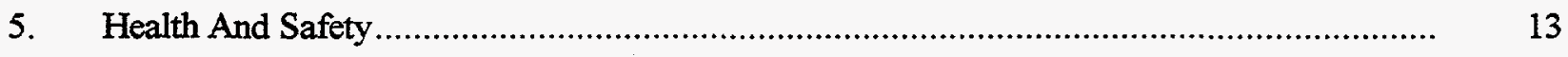

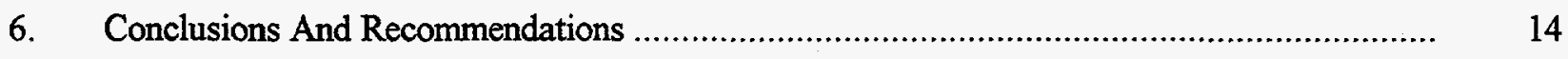

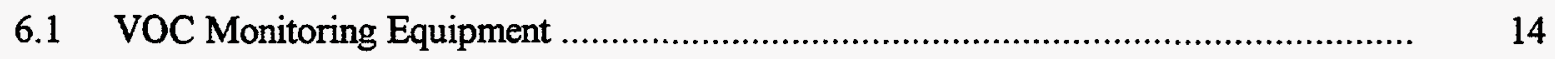

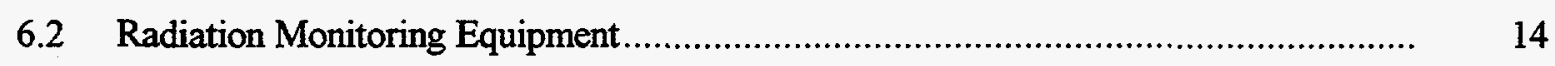

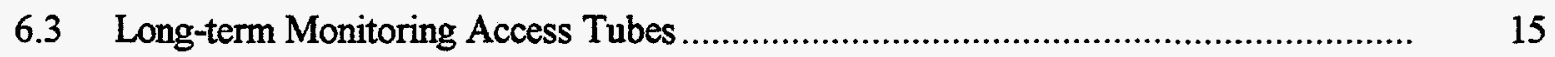


Appendix A .............................................. Calculations for Diameter of Access Tubes

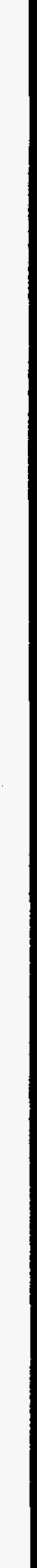




\section{PROJECT SUMMARY}

The Buried Waste Containment System (BWCS) is a joint research and development project between Lockheed Martin Idaho Technologies Company (LMITCO) and RAHCO International, for the U.S. Department of Energy (DOE). The purpose of the project is to provide an effective, cost efficient alternative to existing technologies for remediation of buried waste. This approach excavates around and under waste landfills or plumes and contains them with an underground barrier to effectively and efficiently contain wastes that are potentially harmful to the environment.

The BWCS features a self-propelled, track mounted BPM capable of excavating along side and under a buried waste pit while continuously grouting an instrumented containment barrier in the trench behind it as it advances. The unit is designed to contain a site about $40 \mathrm{ft}$ wide and $18 \mathrm{ft}$ deep, and of unlimited length. The machine will be capable of cutting at rates of 2 to $10 \mathrm{ft}$ per hour, 24 hours per day. While the site is being excavated, the machine lays a 12 to 16-in. under barrier with 6 to 8-in.-thick walls, providing a leak-proof, tub-like, containment around the undisturbed waste.

This report evaluates sensors used to monitor radionuclides and volatile/semi volatile organic compounds encountered during slot cutting and barrier placement activities. Tubes providing access for long-term monitoring will also be evaluated.

Latex modified cement is the barrier material. This mortar type material meets the emplacement properties required and is deployed similarly to conventional cements.

During barrier placement activities, spoils are conveyed through an assay station on the barrier placement machine where they are monitored for volatile organic compounds (VOCs) and radionuclides. For monitoring VOCs during emplacement activities, the Fourier-Transform Infrared Spectrometer (FTIR) system is preferred because of the maturity of the technology and the availability of technical data. Various radiation detectors can be used to screen the excavated material. If radionuclides are detected by the screening method, the spoils will be examined using a gamma spectroscopy system with a germanium detector to detect the isotope and radiation level.

Long-term integrity of the containnent barrier will be measured using fiber-optic sensors emplaced in the barrier material to monitor for strain and cracking in the material. In addition, access tubes used to house bundles of scintillation fibers to monitor for radionuclides and a fiber-optic coupled spectroscopy system to monitor for VOCs will be placed directly into the barrier material during emplacement. The access tubes provide a method of removing, adding, or changing instruments and sensors to the long term monitoring system.

Five potential sites were chosen for a proof of principle test: Pacific Northwest National Laboratories (PNNL) in Washington, the Tonapah Test Range in Nevada, the Idaho National Engineering and Environmental Laboratory (INEEL) in Idaho, Sandia National Laboratory in New Mexico, and the Pantex Plant in Texas. The selected site would need to be analyzed for the type of hazards present at that location. 


\section{EVALUATION OBJECTIVES}

The objective of this report is to evaluate different monitoring technologies and recommend a technology to further develop each application. These monitoring methods will be used with the BWCS to detect the presence of VOCs and radiation during barrier emplacement, and leakage through the containment during long-term storage. Specifically, BPM mounted sensors, to monitor the excavated spoils for radiation and VOCs, and access tubes, embedded in the containment barrier to monitor for radiation and VOC leaks, will be used.

Technologies in the three areas mentioned above will be evaluated based on maturity of the technology, availability of technical data, cost, risk, and efficiency. One technology will be recommended for each.

The purpose of this evaluation is to review existing technologies and quickly narrow the options to a single technology and perform scoping research on that selected technology. This scoping research is needed to provide preliminary design information for the design and development of the BPM. It is not intended to be a detailed design but will rather provide envelope sizing, concept description, and rough order magnitude cost estimates.

\subsection{Volatile Organic Compound}

As the barrier placement machine advances it excavates spoils from the sides and from a slot under the site to be contained. The spoils are conveyed up and out the back of the BPM. A method is required to monitor these spoils for presence of VOCs. This monitoring method needs to identify the presence, type, and location of the VOCs. The VOC sensors need to monitor the spoils after excavation and before they are returned to the site.

This objective of this evaluation is to identify the process, the equipment, and the approximate cost for this method.

\subsection{Radiation Sensors}

Between excavating and returning the spoils to the site, they must be monitored for radiation and VOCs. BPM mounted sensors are required to detect radiation in the excavated waste. If radiation is detected above a predetermined threshold, other sensors will be required to further determine the energy spectrum.

The objective of this evaluation is to identify the process, the equipment, and the approximate cost for this method. 


\subsection{Long-term Monitoring Access Tubes}

Access tubes will be placed in the barrier material during barrier emplacement to provide a mechanism to monitor for VOCs and radiation migration through the barrier. The objective of this evaluation is to make preliminary recommendations for size, material, and geometry for these access tubes. 


\section{REQUIREMENTS AND ASSUMPTIONS}

The following list of requirements and assumptions were used in the development of the evaluations in this report. Additional requirements and assumptions will be identified as the project progresses and as site specific requirements are defined.

- Threshold limits will be site specific and the equipment must provide a method for changing limits.

- Detection of unsuspected contamination, VOCs, or radionuclides above threshold limits will suspend placement activities.

- Site regulators will require removed topsoil to be replaced at the site as part of the site restoration.

- Operations can be performed under open-air conditions without the need to capture airborne particulate, filter dusts or gases, etc.

- Computer equipment and instrumentation will be capable of operating under hostile conditions encountered during this type of operation, such as vibration, shock, etc.

- The BPM will be capable of detecting VOCs and radiation, and will identify their point source during placement activities. A Global Positioning System (GPS) will be used to position the BPM.

- Emplacement operations will only be performed during the following environmental conditions: ambient air temperature between 10 and $49^{\circ} \mathrm{C}$, wind to $10 \mathrm{mph}$ with gusts to $20 \mathrm{mph}$, and precipitation 0 in. These restrictions are based on the allowable operating conditions of the BPM.

- The air above the spoils will be sampled for VOCs as it passes by the sampling station. 


\section{TECHNOLOGY EVALUATION}

The purpose of this evaluation is to review existing technologies, narrow the options to a single technology, and perform scoping research on that selected technology. Scoping research will be used to provide preliminary information to design and develop the BPM. It is not intended to be a detailed design but will rather provide envelope sizing, concept description, and rough order magnitude cost estimates.

\subsection{VOC Monitoring Equipment}

Prior to initiating the technology evaluation, a list of potential instruments to rapidly monitor VOCs on-line during the digging operation was developed. This list forms the basis of this evaluation. The list includes: (1) Gas Chromatography/ Mass Spectrometry (GC/MS), (2) Acoustic-Optic Tunable Filter (AOTF) Infrared Spectrometer, (3) Heated Carbon Analyzer with Photo Acoustic Infrared Spectrometry (PAS), and (4) Fourier-Transform Infrared Spectrometer (FTIR) system.

Of the four technologies, the GC/MS and the AOTF were eliminated by cursory investigation for reasons described below. The two remaining technologies were evaluated in more detail.

\subsubsection{Gas Chromatography/ Mass Spectrometry (GC/MS)}

The GC/MS instrument has many disadvantages: (1) its response time is on the order of several minutes; (2) it will only identify those gases assumed to be there; (3) it ionizes the gases and therefore destroys the sample, precluding additional tests; and (4) it requires daily calibration. Because of these disadvantages, this technique was not pursued further.

\subsubsection{Acoustic-Optic Tunable Filter (AOTF) Infrared Spectrometry}

The AOTF was not pursued further because of the lack of maturity of the AOTF technology and the unavailability of technical data.

\subsubsection{Heated Carbon Analyzer with Photo Acoustic Infrared Spectrometry (PAS)}

The PAS monitoring technology evaluated is comprised of two systems: (1) a heated carbon analyzer that identifies the presence of VOCs, and (2) a photo acoustic infrared spectroscopy system (PAS) that identifies the compounds and concentration levels.

The heated carbon analyzer continuously measures the presence of hydrocarbons within a gaseous sample by using the flame ionization method. The analyzer will detect the presence of hydrocarbons, but will not identify them. A sample is then passed to the PAS to identify the compounds and their concentrations. Two models of the heated carbon analyzer are listed for comparison: 
- HNU Model 201-FID, [HNU Systems Inc., Newton MA, (617) 964-6690]

Operating principle: $\quad$ Flame ionization

Sensitivity: $\quad 0.1 \mathrm{ppm}$

Response time: $\quad 3$ seconds

Sampling rate: Continuous

Operational environment: $\quad 15-50^{\circ} \mathrm{C}, 10-90 \%$ humidity

Power requirements: $120 \mathrm{VAC}$

Weight: $\quad 45 \mathrm{lb}$.

Dimensions: $\quad 19$ in. $\mathrm{W} \times 11$ in. $\mathrm{H} \times 25$ in. D

Price: $\quad \$ 20 \mathrm{~K}$.

- California Analytical Instruments, Model 300-HFID, [SELTECH, Bellevue WA, (206) 882-9600]

$\begin{array}{ll}\text { Sensitivity: } & 0.1 \mathrm{ppm} \\ \text { Operating principle: } & \text { Flame ionization } \\ \text { Response time: } & 1.5 \text { seconds } \\ \text { Sampling rate: } & \text { Continuous } \\ \text { Operational environment: } & 15-50^{\circ} \mathrm{C}, 10-90 \% \text { humidity } \\ \text { Power requirements: } & 120 \mathrm{VAC} \\ \text { Weight: } & 50 \mathrm{lb} . \\ \text { Dimensions: } & 19 \text { in. W } \times 6 \text { in. } \mathrm{H} \mathrm{x} 23 \text { in. D } \\ \text { Price: } & \$ 20 \mathrm{~K} .\end{array}$

The PAS operates on the principle known as the photo acoustic effect, which is the emission of sound by an enclosed sample upon the absorption of chopped light. When a gas is irradiated with light, it absorbs some of the energy in proportion to its concentration. The absorbed light energy is immediately released as heat, causing the pressure to rise. When the light is modulated at a given frequency, the pressure increase modulates as well. Pressure waves (sound waves) are measured with a microphone.

Contaminants will be site specific and may vary from those listed below. For purposes of this evaluation, the following list of VOC contaminants, specific to the Subsurface Disposal Area at the INEEL, was used:

\author{
carbon tetrachloride \\ trichloroethylene \\ 1,1,1-trichloroethylene \\ chloroform \\ tetrachloroethylene \\ 1,1,2-trichlorotrifluoroethane \\ 1,1-dichloroethane \\ dichlorodifluoromethane \\ toluene.
}

The list of VOCs was supplied to the manufacturers of the PAS methods. Vendor information was obtained and summarized below. Two models are listed for comparison: 
- Innova Model-1301, [INNOVA, Orange CA, (714) 974-5560]

Operating principle:

Sensitivity:

Response time:

Sampling rate:

Operational environment:

Power requirements:

Weight:

Dimensions:

Price:
Photo Acoustic IR Spectroscopy

low ppm

1 minute

1 sample per minute

$15-50^{\circ} \mathrm{C}, 10-90 \%$ humidity

$120 \mathrm{VAC}$

$40 \mathrm{lb}$.

17 in. $W \times 8$ in. $H \times 20$ in. D

$\$ 80 \mathrm{~K}$.

- Innova Model-1312, [INNOVA, Orange CA, (714) 974-5560]

Operating principle:

Sensitivity:

Response time:

Sampling rate:

Operational environment:

Power requirements:

Weight:

Dimensions:

Price:
Photo Acoustic IR Spectroscopy

high ppb

40 seconds

1 sample per minute

$15-50^{\circ} \mathrm{C}, 10-90 \%$ humidity

$120 \mathrm{VAC}$

$20 \mathrm{lb}$.

16 in. $W \times 7$ in. $H \times 12$ in. D

$\$ 100 \mathrm{~K}$.

The heated carbon analyzer measures continuously with resolution of $0.01 \mathrm{ppm}$, and a response time of 1.5 seconds. The PAS samples at approximately 1 sample/ minute with resolution in the high ppb and only requires calibration every three months to a year.

A drawback to the PAS is the requirement for the light source to be tuned for the compounds being measured. Therefore one must know what compounds are expected prior to using the instrument. The PAS instrument is vibration sensitive and will probably need to be mounted off the BPM.

\subsubsection{Fourier-Transform Infrared Spectrometry (FTIR) System}

FTIR uses an interferometer in place of a grating to analyze the absorption spectrum. This device consists of a light source, a beam splitter, and two mirrors. When one mirror is moved, interference is created at each wavelength. The beam is then transmitted across the sample and focused onto a detector element. Electronics record the intensity as a function of mirror position, creating an interferogram, which is converted by a Fourier transform into a spectrum of intensity versus wave number.

\section{Expected Operation:}

Wavelength of Operation:

Power requirements:

Sensitivity:

Response time:

Sampling rate:

Operational environment:
2.5-16 microns with a resolution of $0.5 \mathrm{~cm}^{-1}$

$120 \mathrm{VAC}$

low ppm or better

Spectral Discrimination, 1-5 seconds

$10 \mathrm{ft}^{2} / \mathrm{min}$

$15-50^{\circ} \mathrm{C}, 10-90 \%$ humidity. 
Two general FTIR methods were considered. Method one pulls a gas sample into a chamber, or cell, through a filter and performs its analysis on the cell sample. Method two, open path FTIR, shoots the light across the area of interest and reflects it back to the spectrometer.

Method one (grab sample FTIR):

- Air Century FTIR, Model 28200, [Environmental Technologies, Baltimore, MD, (410) 3215215]

Wavelength of Operation:

Power requirements:

Sensitivity:

Response time:

Sampling rate:

Operational environment:

Weight:

Dimensions:

Price:
1.5-14 microns, resolution $4 \mathrm{~cm}^{-1}$

$120 \mathrm{VAC}$

low ppb

Spectral Discrimination, 10 seconds

$10 \mathrm{ft}^{2} / \mathrm{min}$

$15-50^{\circ} \mathrm{C}, 10-90 \%$ humidity

$100 \mathrm{lb}$.

12 in. $\mathrm{W} \times 24$ in. $\mathrm{H} \times 24$ in. D

$\$ 100 \mathrm{~K}$

Can shock mount to BPM.

Very stable (It has a calibration cell built into it and self checks as required).

Method two (open path FTIR):

- Block Engineering Model-100, [Block Engineering, Marlborough MA, (508) 480-0643]

Wavelength of Operation:

Power requirements:

Sensitivity:

Response time:

Sampling rate:

Operational environment:

Weight:

Dimensions:

Price:

Can shock mount to BPM.

Very stable.
1.5-14 microns, resolution $2 \mathrm{~cm}^{-1}$

120 VAC

low ppb

Spectral Discrimination, approximately 10 seconds

$10 \mathrm{ft}^{2} / \mathrm{min}$

$15-50^{\circ} \mathrm{C}, 10-90 \%$ humidity

$12 \mathrm{lb}$.

6 in. $W \times 6$ in. $H \times 9$ in. $D$

$\$ 125 \mathrm{~K}$

- Block Engineering Model-500, [Block Engineering, Marlborough MA, (508) 480-0643]

Wavelength of Operation:

Power requirements:

Sensitivity:

Response time:

Sampling rate:
1.5-14 microns, resolution $2 \mathrm{~cm}^{-1}$

$120 \mathrm{VAC}$

low ppb

Spectral Discrimination, approximately 1 second $10 \mathrm{ft}^{2} / \mathrm{min}$ 
Operational environment:

Weight:

Dimensions:

Price: $15-50^{\circ} \mathrm{C}, 10-90 \%$ humidity

$30 \mathrm{lb}$.

12 in. $\mathrm{W} \times 8$ in. $\mathrm{H} \times 18$ in. $\mathrm{D}$

$\$ 150 \mathrm{~K}$

Can shock mount to BPM.

Very stable.

Of the two methods listed, the open path FTIR (method two) has the following advantages and is recommended over the grab sample FTIR (method one): (1) no filter is required; (2) it has a faster response time; and (3) it can beam the light either across the conveyor belt, or use a wide beam and direct it onto the spoils on the belt. Of the two open path FTIRs listed, the Block Engineering Model-500 is recommended because it is rugged, yet has the highest sensitivity and sampling rates.

\subsection{Radiation Monitoring Equipment}

A radioactive characterization method (assay station, handheld monitors, and counting stations) is needed to provide rapid measurements to map the activity as a function of position, identify the radionuclides present at various positions, and quantify the amount of radionuclides present.

Low level detection (LLD) measurements depend upon the background conditions of the monitored area. Background radiation levels are site specific and local area specific. Background levels must be determined and measurement equipment set at a setpoint above the measured background levels.

The following radioactive characterization method is recommended for BWCS barrier emplacement operations. Radiation monitoring for alpha, beta, and gamma radiation will be required on all excavated spoils. Setpoints can be set to site specific predetermined values. Indications and alarms will be routed to a central control booth. Readouts and alarms will be available both locally and in the control booth. If alarms or setpoints are reached, the emplacement machine is stopped and hand held equipment will monitor the above normal reading. Once the abnormal reading is resolved, an operational decision will be made and the operation will continue or stop. If desired, samples can be taken and delivered to a nearby counting station to gain better resolution of the sample.

\subsubsection{Assay Station}

A radiation monitoring assay station contained on each conveyor belt would monitor beta particles and gamma rays. One of three types of detectors could be used. The germanium detector will give fine resolution to $1.5 \mathrm{KeV}$, but requires liquid nitrogen cooling making it fragile and sensitive to vibration. Sodium iodide scintillation [Na(TI)] detectors work well, with energy resolution in the $50 \mathrm{KeV}$ range, but several would be required (approximately 8-10) to cover each conveyor belt. These detectors need to be calibrated to one another to match energy pulses, if not, the cumulative energy resolution band could be very large. These detectors are also temperature and vibration sensitive. The plastic scintillator is more durable and not temperature sensitive. Energy data coming into the detector can be used to perform a 
multichannel analysis of the signal to determine several energy peaks. The plastic scintillator is the detector of choice based on its durability and temperature tolerance and is discussed below.

Each assay station will consist of two detectors on each side. The detectors have a $0.01 \mathrm{in}$. thick mylar window protected by a thin plastic screen to let the maximum amount of radiation pass through. The method would analyze the energy of the decay gamma and hard beta (betas with high energy) and display an energy spectrum showing data from $\mathrm{KeV}$ to $\mathrm{MeV}$. The computer system monitoring the radiation could be the same unit used for receiving and displaying the VOC information.

One system will be required for each conveyor. Each assay system consists of two organic plastic detectors with photo multiplier tubes ( PMTs), a light guide, and a voltage divider. One, two-channel amplifier/single channel analyzer (SCA) will provide high voltage and signal processing for the detectors. Each detector will have a dedicated amplifier and digital output to the counters in the computer located in the operator's cab on the BPM.

System software will provide diagnostic modes to assist in analyzing system operation, as well as background acquisition, scanning, and alarm calculations.

The system described above is a plastic scintillator type, TSA Model WM-289 Waste Monitoring System [SELTECH, Bellevue WA, (206) 882-9600]:

- Detector - plastic scintillator-12 in. x $30 \mathrm{in}$. $x 1.5$ in. weighing $35 \mathrm{lb}$. Price is $\$ 25,000$ per pair.

- Computer-1 $\mathrm{ft} \times 1 \mathrm{ft} \times 2 \mathrm{ft}$ weighing $25 \mathrm{lb}$. Price is $\$ 25,000$.

Cost is approximately $\$ 75,000$ for the onboard radiation monitoring system for two conveyors. Two conveyors would consist of two pairs of detectors and one computer.

\subsubsection{Survey Monitors}

If radiation is detected by the assay station above a predetermined level, the BPM will be stopped and hand held devices will be used to monitor the spoils to provide a better indication of the radionuclides present. Two types of hand held equipment are required, one to measure beta and gamma, and one to measure alpha.

- The Bicron Model G5-BELBR is a low background rugged fiddler gamma scintillation probe for detection of low-energy $x$-ray, beta, and gamma radiation. The price is $\$ 6,800$. The Bicron Model ANALYST portable ratemeter with two single channel analyzers is also needed to use the Bicron Model G5-BELBR. The price is \$980. [BICRON, Newbury OH, (216) 564-2251].

- The SAIC Model AP-2 Portable Alpha Spectrometer Survey Instrument allows the discrimination of radon while looking for other alpha radiation. The price is $\$ 4,200$. [SAIC, San Diego CA, (708) 2159600].

\subsubsection{Counting Stations}

Identification of specific radionuclides is required by the Code of Federal Regulations (CFR), 10 CFR 835. The CFR requires information on the isotope and the quantity discovered. This could be accomplished by sending samples to another facility or laboratory, but the time delay would be 
unacceptable to BWCS operations. Two systems are needed to provide this data, one is the alpha/beta counter and the other is the gamma germanium counter. These systems would be located separate from the BPM, but on station in the local area of BPM operations.

- Oxford/Tennelec Model LB41-FP-121 Alpha/Beta Simultaneous Manual Counting System [Oxford Instruments Inc., Oak Ridge TN, (423) 483-8405]

Low background capability: Alpha background, $0.1 \mathrm{cpm}$, Beta ,0.9 cpm

Multi-detector configurations

Multiple detector selection: 1.25 in., 2.25 in., 3.25 in., or 5.25 in.

High Performance 2.25 in. gas flow detector, with ultra thin window $80 \mathrm{microgram} / \mathrm{cm}^{2}$

Size 50 in. $\times 25.5$ in. $\times 27.5$ in.

Weight $-2700 \mathrm{lb}$

Price- $\$ 31,700$.

- Oxford/Tennelec Gamma Germanium Sample Counting System [Oxford Instruments Inc., Oak Ridge TN, (423) 483-8405]

Useful range- $3 \mathrm{Kev}$ to $10 \mathrm{Mev}$

Requires liquid nitrogen cooling

CN Series Detector consists of an HPGe detector element

Cryostat end-cap fitted with a Beryllium entrance window for low energy photon detection 8192 Channel Multi-Channel Analyzer Card 5 microsecond successive approximation $\mathrm{ADC}$

Size-17.5 in. dia. $x 36$ in. $H$, with the H.P computer 12 in. $x 12$ in. $x 24$ in.

Weight-2400 lb

Price- $\$ 35,495$.

The equipment identified above is standard, proven, readily available, and currently in use at many different DOE sites.

Total cost for radiation instrumentation including assay stations on the BPM, survey monitors, and the counting stations in a remote location is approximately $\$ 155,000$.

\subsection{Long-term Monitoring Access Tubes}

To ensure that the containment barrier is not breached and still provides the level of containment desired, access tubes will be installed in the barrier to allow monitoring of VOCs and radiation for the life of the barrier. The Code of Federal Regulation, 40 CFR 264, Subpart N, Section 264.303 requires liners to be inspected and monitored during installation. There is no specific requirement for monitoring during the active life of the liner. However, there are requirements for a leachate collection method and a double liner when installing a containment for new waste. There are no such requirements for in situ containment, however, in an effort to meet the intent of the leachate method and double liner requirements, this project provides access tubes in the barrier to monitor VOCs and radionuclides that might leak through the containment. Access tubes will be located in the barrier material near the outside surface of the barrier. 
Instrumentation can be installed in the access tubes, after the containment barrier is completed, for longterm monitoring.

The initial estimate for detection of radiation will require the tubes to be located at $1 \mathrm{ft}$ intervals. The spacing of sensors inside the access tubes will require 80 detectors located $1 \mathrm{ft}$ apart along the length. The fiber optic radiation detection bundle will be approximately $1 \mathrm{in}$. in diameter. Additional investigation is needed on the VOC fiber optic sensor geometry, but an estimate of the VOC sensor bundle is approximately $1 \mathrm{in}$. in diameter. Based on these estimates a minimum diameter for the tubing is 2 in. To allow room for bending and installation of the fibers, a 3 in. internal diameter tube is recommended. Minimum bend radius on the tubing is $10 \mathrm{in}$. based on the minimum bend radius of the fiber optic bundle.

The long-term monitoring access tubes need to be open to the elements to allow VOCs to enter the void space in the tubes. Perforation of the tubes will be done after barrier emplacement to keep the barrier material from plugging the tube. Two methods are available for performing this function: one uses a laser with a 2 in. diameter turning optic mirror and the other uses high pressure frozen gas. Perforation geometry is yet to be determined and is partly contingent on the requirements of the VOC fiber optic sensors.

Requirements in "Preliminary Design Requirements for a Buried Waste Containment System", INEL-96/0458, state that we need a tube, flexible to $-40^{\circ} \mathrm{F}$ that will last for 100 years. This could not be located; however, polyvinyl chloride (PVC), PAC-FLEX Flexible conduit (made by Pacific Echo Inc., Torrance CA, (800) 421-5196) is a viable substitute and has been in service for 30 years. The temperature range of the conduit is -10 to $+130^{\circ} \mathrm{F}$ and the manufacturer will guarantee it for 20 years within that range. When the temperature drops below $-10^{\circ} \mathrm{F}$ the PVC becomes brittle and migration of the polymer chains occurs, weakening the material. If the PVC tubing were to breakdown, an auger device could be run the length of the tube removing the broken pieces leaving a $3+$ in. diameter unlined hole in the barrier. This is also an option for initial installation, i.e., place a disposable liner during emplacement and ream the entire liner out rather than perforating. The only anticipated exposure to $-40^{\circ} \mathrm{F}$ is in the upper $4 \mathrm{ft}$ of access tube where it is near the surface of soil. It is beyond the scope of this evaluation but it seems reasonable to assume that there are engineered solutions to this scenario.

Other types of tubing investigated were metal, rubber, teflon and cryogenic tubing. The metal tubing has the disadvantage of not being flexible and would require cathodic protection. Rubber has problems with microbial attack when buried in soil. Teflon becomes powder like when subjected to $10^{4}$ to $10^{6} \mathrm{rad}$, only comes in $10 \mathrm{ft}$ lengths, and is expensive. Cryogenic tubing is good to $-25^{\circ} \mathrm{F}$ but has a rubber compound, and is approximately 3 times the cost of flexible PVC.

Flexible PVC is the recommended material for the access tubes. The tubes should have a minimum inside diameter of 3 in. and accommodate a 10 in. minimum bend radius. Tubes should be spaced at a maximum of $12 \mathrm{in}$. center to center based on the requirements for radiation monitoring. It should be noted that this might change based on risk if demonstrated by risk analysis. 


\section{HEALTH AND SAFETY}

The governing document for the DOE complex-wide radiological control program is 10 CFR 835 "Occupational Radiation Protection; Final Rule." This document contains the Federal Regulations for implementation of the BWCS program. The following is applicable only if the BWCS operates at the INEEL. The INEEL Radiological Control Manual (RCM) represents the LMITCO and DOE Idaho Operations Office controlling document for radiological work at the INEEL. The RCM includes the applicable requirements to implement 10 CFR 835 . Although the RCM is considered the governing document, lower tier documents clarify requirements and provide specific direction. All of these directions are contained in the company wide Radiation Protection Management Control Procedures (MCPs).

Construction and Restoration projects, including decontamination and decommissioning (D\&D), remedial action, or other actions involving materials containing low levels of radioactivity may present special problems and require the development of site specific control methods in addition to the existing program as identified above. Health and Safety Plans are normally developed to specify control types for all restoration programs.

The requirements of Article 371 of the INEEL RCM apply to the development of the radiological control program for this project. The requirements for postings are contained in the RCM Chapter 2 Part 3 and implemented by MCP-187 "Posting Radiological Areas" and MCP -139 "Radiological Surveys". Access control requirements are contained in RCM Chapter 3 Part 3 and implemented by MCP-7 "Radiological Work Permit." These sections include implementation requirements for the radiological survey program. Radiological work control requirements are contained in RCM Chapter 3 Part 3 and implemented by MCP-7 "Radiological Work Permit." The limits for contamination and radiation identified in Chapter 2 of the RCM will need to be applied to this program. These will establish the bottom line monitoring requirements for the excavation. The radiation detection equipment for the BWCS will be required to detect alpha, beta and gamma radiation.

Site specific requirements will need to be developed for each end-user site. 


\section{CONCLUSIONS AND RECOMMENDATIONS}

\subsection{VOC Monitoring Equipment}

Based on BPM operating conditions, a FTIR system is the recommended measurement method because of its high sensitivities and sampling rates, and because it is rugged enough to be mounted to the BPM directly. In addition, it records a spectrum for each scan, which can be reviewed later to look for other gases that may have been missed. The spectrums can also be used to prove other gases were not present in the spoils.

There were two general FTIR methods considered. Method one pulls a gas sample into a chamber, or cell, through a filter and performs its analysis on the cell sample. Method two, called open path FTIR, shoots the light across the area of interest and reflects it back to the spectrometer. Of these two methods, the open path FTIR (method two) has the following advantages and is recommended over the grab sample FTIR (method one): (1) no filter is required; (2) it has a faster response time; and (3) it can beam the light either across the conveyor belt, or use a wide beam and direct it onto the spoils on the belt. Of the two open path FTIRs evaluated, the Block Engineering Model-500 is recommended because it is rugged and yet has the highest sensitivity and sampling rates. Cost is approximately $\$ 125,000$ for each assay station assuming one assay station per conveyor.

Two companies that supply VOC monitoring equipment [Environmental Technologies; Baltimore, MD (410) 321-5215 and Block Engineering; Marlborough, Mass (508) 480-9643] have offered to let us test and evaluate the equipment. This work could be performed at the INEEL or done with a University.

\subsection{Radiation Monitoring Equipment}

The radiation monitoring method includes assay stations, handheld monitors, and counting stations. One assay station is required on each conveyor. Each assay station consists of two organic plastic scintillator type detectors with photo multiplier tubes (PMTs), a light guide, and a voltage divider. One, two-channel amplifier/single channel analyzer (SCA) will provide high voltage and signal processing for the detectors. Each detector will have a dedicated amplifier and digital output to the counters in the computer located in the operator's cab on the BPM.

System software will provide diagnostic modes to assist in analyzing system operation, as well as background acquisition, scanning, and alarm calculations. Data is fed from the assay stations to computers located in the operator's cab. The computer system monitoring the radiation could be the same unit used for receiving and displaying the $\mathrm{VOC}$ information.

- This system is a plastic scintillator type, TSA Model WM-289 Waste Monitoring System. Cost is approximately $\$ 75,000$ for the monitoring system for two conveyors, including a computer. 
If radiation is detected by the assay station above a predetermined level, the BPM will be stopped and hand held devices will be used to monitor the spoils to provide a better indication of the radionuclides present. Two types of hand held equipment are required, one to measure beta and gamma, and one to measure alpha.

- The Bicron Model G5-BELBR is a low background rugged fiddler gamma scintillation probe for detection of low-energy $\mathbf{x}$-ray, beta, and gamma radiation. Price is $\$ 6,800$. The Bicron Model ANALYST portable ratemeter with two single channel analyzers is also needed to use the Bicron Model G5-BELBR. Price is $\$ 980$.

- SAIC Model AP-2 Portable Alpha Spectrometer Survey instrument allows the discrimination of radon while looking for other alpha radiation. Price is $\$ 4,200$.

Identification of specific radionuclides as required by the Code of Federal Regulations could be accomplished using two counting stations: an alpha/beta counter and a gamma germanium counter.

- Oxford/Tennelec Model LB41-FP-121 Alpha/Beta Simultaneous Manual Counting System. Price is $\$ 31,700$.

- Oxford/Tennelec Gamma Germanium Sample Counting System. Price is $\$ 35,495$.

Total cost for radiation instrumentation, including assay stations on the BPM, survey monitors, and the counting stations in a remote location. Price is $\$ 155,000$.

\subsection{Long-term Monitoring Access Tubes}

The recommended tubing for the long-term access tube is the PVC PAC-FLEX Flexible Conduit, Spiralite 850 in nominal 3 in. size. This tubing has a recommended minimum bend radius of 8 in., costs $\$ 3.26$ per $\mathrm{ft}$, and is available in $100 \mathrm{ft}$ lengths. This tube is temperature rated at $-10^{\circ} \mathrm{F}$ to $+130^{\circ} \mathrm{F}$. Based on the requirements for radiation detection, the ideal spacing would be on $12 \mathrm{in}$. centers.

A material that may meet the $-40^{\circ} \mathrm{F}$ temperature requirement and last for the 100 year time frame is high density polyethylene (HDPE), used to make underground holding tanks, but it needs to be investigated further for this application.

Testing the laser, or high pressure gas, or both to perforate the tubing should be performed prior to final design. This testing would take approximately 2 weeks to complete. It would be advantageous to perform the test in near field conditions, i.e. embedded in the barrier material.

A 3 in. diameter tube is recommended. Calculations for the diameter of the access tube are in Appendix A. 
Appendix A

Calculations for Diameter of Access Tubes 


\section{Appendix A}

\section{Calculations for Diameter of Access Tubes}

Fiber $2 \mathrm{~mm} \varnothing=0.079$ in. $\varnothing=\mathrm{d}$

$\mathrm{K}=10.539$ For arrangement " $\mathrm{B}$ " (" $\mathrm{B}$ " is the worst case circle pattern)

Number of cables $=80=n$

$\mathrm{D}=$ Id of tube

$\mathrm{D}=\mathrm{Kd}$

$D=10.53(0.079$ in. $)=0.83$ in. $\varnothing$

Add 0.03in. $\mathrm{r}$ space and add 0.03 in. thick sheath $=0.06$ in. $\mathrm{r}$

Diameter $=2(\mathrm{r}$ space and sheath $)=0.12 \mathrm{in}$.

Total diameter $=0.83$ in. $\varnothing$

$$
+0.12 \text { in. } \varnothing
$$

0.95 in. diameter for fiber optic bundle

The bundle may not stay round so lin. diameter will be used for initial estimates.

1 tube for Radiation 1 in.

$\frac{1 \text { tube for VOCs }}{\text { Total diameter }} \frac{+1 \text { in. }}{2 \text { in. }}$

With a 2 in. diameter combination, a 3 in. diameter tube is recommended. This would leave a little spacing for inserting the tube bundles, allowing for out-of-round bundles and allowing for possible slight variations in the bend radius of the 3 in. diameter access tubes when they are installed in the containment barrier. 